\title{
RACISMO AMBIENTAL E APLICAÇÃO DIFERENCIADA DAS NORMAS AMBIENTAIS: UMA APROXIMAÇÃO NECESSÁRIA ENTRE OS CASOS DA COMUNIDADE DO HORTO FLORESTALEDO CONDOMÍNIO CANTO E MELLO (GÁVEA/RJ)
}

ENVIRONMENTAL RACISM AND THE DISPARATE APPLICATION OF ENVIRONMENTAL LAWS: THE NECESSARY MERGING OF HORTO FLORESTAL COMMUNITY AND THE CANTO E MELLO CONDOMINIUM CASES (GÁVEA/RJ)

Virgínia Totti Guimarães*

Paula Máximo de Barros Pinto**

*Professora do Departamento de Direito da Pontifícia Universidade Católica do Rio de Janeiro (PUC-Rio) e doutora em Direito pela PUC-RIO.

**Graduanda em Direito pela Pontifícia Universidade Católica do Rio de Janeiro (PUC-Rio) e pesquisadora de iniciação científica. 


\section{RESUMO}

O artigo discute a aplicação diferenciada da legislação ambiental a partir do caso da Comunidade do Horto Florestal, utilizando análise comparativa em relação a outro caso bem próximo, ao menos do ponto de vista físico: o Condomínio Canto e Mello. A remoção de moradores do Horto, inclusive com o uso de argumentos ambientais para justificá-las, é um dos capítulos de racismo ambiental na cidade do Rio de Janeiro. O racismo ambiental é produzido por uma série de atos e omissões do Poder Público, mencionando-se a não adoção de ações para regularização fundiária em imóvel público para moradores que residem no local há décadas com base em manifestas e reiteradas permissões da União, bem como a prática de medidas diretamente relacionadas à remoção dos moradores. Os moradores do Horto, nesse sentido, suportam parcela desproporcional das consequências ambientais e, especificamente, acessam menos recursos ambientais presentes nos territórios.

PALAVRAS-CHAVE: Horto Florestal; Condomínio Canto e Mello; racismo ambiental; injustiça ambiental; aplicação diferenciada da legislação ambiental.

\section{ABSTRACT}

This paper discusses the disparate application of environmental laws through the Horto Florestal Community case, in particular, by conducting a comparative analysis of the case to another, geographically similar, example: the Canto e Mello Condominium. The use of environmental arguments to remove the Horto residents is just another chapter in Rio de Janeiro's environmental racism problem. This environmental racism is the product of a series of actions and omissions by Political Authorities, including the non-regularization of people who have resided in public lands for decades based on manifests and permissions reiterated by the Federal Union, as well as measures directly related to the removal of residents. The residents of Horto, in this sense, bare a disproportional share of the environmental consequences, and have access to fewer environmental resources that are present in the area.

KEYWORDS: Horto Florestal; Canto e Mello Condominium; environmental racism; environmental justice; disparate aplication of envionmental laws. 


\section{Introdução}

As tentativas de remoção da Comunidade do Horto Florestal, na zona sul da cidade do Rio de Janeiro, têm se mostrado como mais um dos capítulos emblemáticos de racismo ambiental e aplicação desigual da legislação ambiental, inclusive com a utilização de argumentos ambientais para reforçar as políticas de expulsão dos moradores de baixa renda, que residem no local há décadas, com base em manifestas e reiteradas permissões do Poder Público.

Este artigo tem como objetivo discutir a aplicação diferenciada da legislação ambiental incluindo o peso e a importância que se dá às normas -, a partir do caso do Horto, destacando-se as medidas que vem sendo tomadas pelo Poder Público, chegando à situação atual, em que os moradores são tratados individualmente, e não como uma coletividade, sendo que cerca de 600 famílias são rés em ações de reintegração de posse propostas pela União.

Muitas vezes, o caso do Horto evoca outra situação muito próxima, ao menos do ponto de vista físico: o Condomínio Canto e Mello. Dentre essas menções, citam-se as provocações feitas por Fernandes em mais de uma oportunidade,${ }^{1}$ bem como a comparação feita em Silva (2OIO) que analisa as contradições dos discursos da ilegalidade urbana.

Pretende-se, nesse sentido, apresentar o caso do Condomínio Canto e Mello, composto por casas de alto padrão, localizado parcialmente no interior do Instituto de Pesquisas Jardim Botânico, ${ }^{2}$ no bairro da Gávea, e que, embora tenha sido objeto de ação judicial, obteve o direito de permanecer no local, em área bastante preservada e sem nenhuma autorização inicial do Poder Público (ao contrário, representantes da prefeitura do Rio de Janeiro, quando provocados, afirmaram a impossibilidade de construção diante das normas ambientais e urbanísticas).

Neste artigo, inicialmente serão apresentadas as principais discussões sobre a ocupação do Horto e, em seguida, sobre o Condomínio Canto e Mello para, ao final, a partir das noções de racismo ambiental e aplicação desigual da legislação ambiental, aproximá-los com as pertinentes elaborações de cunho teórico.

Para a construção deste artigo, além da pesquisa bibliográfica, utilizam-se informações produzidas em atividade de extensão na Comunidade do Horto, desenvolvida no âmbito da Pontifícia da Universidade Católica do Rio de Janeiro (PUC-Rio), por meio do grupo de pesquisa e extensão Terras e Lutas (Projeto Direitos em Movimento: Territórios e Comunidades), vinculado ao Núcleo de Estudos Constitucionais (NEC) do Departamento de Direito.

\footnotetext{
${ }^{1}$ Por todos, menciona-se Daflon (2013, on-line).

${ }^{2}$ Disponível em: <http://aplicacoes.jbrj.gov.br/divulga/fundiaria/mapa.jpg>. Acesso em: 28 maio 2018.

${ }^{3}$ A atividade de extensão no grupo do Horto compreende o acompanhamento das discussões relativas às ações judiciais, envolvendo estudantes de graduação e da pós-graduação em debates sobre os pressupostos jurídicos das tentativas de remoções em curso, por meio de visitas guiadas, participação em reuniões e realização de mutirões de assistência jurídica. Além disso, a partir do caso do Horto, são feitas pesquisas jurídicas a serem utilizadas em defesa dos moradores, mas que igualmente resultam em um aprendizado prático para os estudantes do curso de Direito da PUC-Rio.
} 


\section{Uma ocupação bicentenária sob ameaça de remoção: o caso da Comunidade do Horto}

A história da cidade do Rio de Janeiro é marcada por desigualdades territoriais, inclusive as produzidas e intensificadas por processos de remoção notadamente caracterizados pelo deslocamento da população negra e pobre das áreas de interesse das elites para regiões periféricas. Por meio de uma disputa desigual com o poder estatal, diversas famílias e comunidades tiveram suas histórias apagadas quando deslocadas de seus territórios, mas, ao mesmo tempo, outras comunidades seguem resistindo para fazerem valer seu direito à moradia. É nesse contexto que se inserem as famílias da Comunidade do Horto que, com sua história de mais de 200 anos, permanece afirmando sua identidade com o território.

Inserida no bairro do Jardim Botânico, na zona sul do Rio de Janeiro, a Comunidade do Horto é composta atualmente por 62I famílias distribuídas em II localidades: Grotão, Morro das Margaridas, Caxinguelê, Chácara do Algodão, Hortão, Clube dos Macacos, Dona Castorina, Vila São Jorge, Pacheco Leão, Solar da Imperatriz e Major Rubens Vaz. ${ }^{4}$

Não cabe, neste artigo, fazer um estudo da história da Comunidade do Horto, mas é importante apontar alguns fatos relevantes da sua consolidação, os quais têm repercussão nos direitos dos moradores.

A ocupação da região teve início em I575, quando apresentava características essencialmente rurais, e foi fundada a Fazenda Nossa Senhora da Conceição da Lagoa Rodrigo de Freitas, inicialmente propriedade real, transferida posteriormente ao Major Domingos Pinto de Miranda e, em seguida, para Diogo de Amorim Soares (MENDONÇA, 20I6b). A extensão do território, à época, correspondia ao que hoje são os bairros Leblon, Ipanema, Lagoa, Fonte da Saudade, Jardim Botânico e Horto; onde se situava um engenho de açúcar e café, responsável pela escravização dos indígenas Tamoios e depois pela introdução da mão de obra negra escravizada da Guiné (SOUZA, 2OI2).

Importa situar o Horto como espaço constitutivo da história da resistência negra no Rio de Janeiro, por consolidar, no Morro das Margaridas, espaço de ligação do Quilombo das Camélias (Leblon) e o Quilombo da Sacopã (Fonte da Saudade), onde a antiga Casa Grande abandonada teria sido utilizada como abrigo para escravos fugidos ou libertos(SOUZA, 2OI2).

A relação dos moradores do Horto com a história da escravidão está viva ainda nos dias de hoje, identificadas a partir das redes de religiosidade africanas presentes no local, bem como pela presença das ruínas de mocambo encontradas no Morro das Margaridas. Nesse sentido, cabe destacar estudos empreendidos por Souza (2012) que remontam tais características a partir de um trabalho de memória-social elaborado com os moradores da Comunidade do Horto, entre os anos de 2008 e 20I2. Um dos entrevistados foi Pai Fausto, morador do Horto, que relata:

\footnotetext{
${ }^{4}$ Disponível em: <http://www.museudohorto.org.br/localidade?id=4354> Acesso em: 02 jun. 2018.
} 
A gente olha pro mato e pensa logo na figura do índio, mas o negro também tem tudo a ver com o mato, até pelo aspecto quilombola. Tem uma herança negra aqui muito grande. Aqui perto da minha casa, a 200 metros tinham grilhões para acoitar os negros, tinha senzala... Aqui existe um lamento negro e todo mundo que trabalha com a espiritualidade aqui sente isso. Meu Pai de Santo Maurício já conversou muitas vezes com a gente a respeito disso. Existe aqui um lamento negro, uma tristeza negra aqui dentro desse lugar. As pessoas passam por cima sem perceber o óbvio, mas é por isso que essas entidades africanas se vinculam muito a esse lugar e sentem necessidade de trabalhar por aqui. A entidade, então, que vem na minha cabeça, ela já me disse que quer ficar aqui, não necessariamente na minha casa, mas é aqui nessa terra que ela quer ficar. Então, existe muito fortemente a presença do negro aqui sim. Espiritual e culturalmente falando.(SOUZA, 2OI2).

Em I809, D. João desapropriou parte da área, que até então era agrícola, para a construção da Fábrica Real de Pólvora. Como consequência da criação da fábrica e da precária mobilidade urbana na época, surgiu a necessidade da permanência dos trabalhadores e suas famílias próximos ao local de trabalho. Para isso, D. João construiu as primeiras vilas operárias da região (MENDONÇA, 20I6b). Em I826, a Real Fábrica de Pólvora foi desativada e as unidade habitacionais, inicialmente direcionadas a seus operários, foram destinadas aos trabalhadores do Imperial Jardim Botânico e das indústrias têxteis posteriormente locadas na região(MENDONÇA, 20I6b).

Em I8II, foi criado o Jardim de Aclimatação, com o objetivo de experimentar o cultivo de espécies exóticas para comercializá-las no Brasil. Ao longo dos anos, diversos nomes foram atribuídos ao jardim: Horto Real, durante a colônia; Imperial Jardim Botânico, na independência; Jardim Botânico, quando seu uso passou a ser público (até então o uso era privativo da família real), e, em 1998, Instituto de Pesquisas Jardim Botânico (IPJB)(MENDONÇA, 20I6a). Em I844, o Jardim Botânico emitiu documento oficial declarando que os 65 trabalhadores do instituto eram negros escravizados, sendo 33 escravos maiores de 7 anos e 32 menores de 7 anos, além de cinco libertos e 26 falecidos. 5

Nos anos I960, a União cedeu parte da área para a implantação de Furnas (1965) e do Serviço Federal de Processamento de Dados(Serpro, I968). Também em I968, o Governo Federal construiu o Conjunto Habitacional Dona Castorina, reconhecido pelos moradores como "Balança", para receber 252 famílias removidas da favela Praia do Pinto, na Lagoa Rodrigo de Freitas.

A partir de 1942, o Horto passou a ser administrado pelo Jardim Botânico, de acordo com regimento do Serviço Florestal Brasileiro. ${ }^{6}$ Contudo, não se menciona qualquer delimitação ou

\footnotetext{
${ }^{5}$ Disponível em: <https://s3-sa-east-1.amazonaws.com/apublica-files-main/wp-

content/uploads/2017/03/16105352/Relac\%CC\%A7a\%CC\%83o-escravos-JB-1844.pdf>. Acesso em: 10 jun. 2018.

${ }^{6}$ Decreto Federal nำ 9.015/1942. Aprova o Regimento do Serviço Florestal.
} 
incorporação territorial entre a Horto e o Jardim Botânico. Em I97I, os 83 hectares que compõem o Horto foram incorporados ao IPJB. ${ }^{7}$ Somente em 2016, a área da União foi doada ao instituto. Importa destacar que historicamente a área ocupada pela Comunidade do Horto e a área utilizada pelo Jardim Botânico nunca se confundiram (MENDONÇA, 20I6a).

Na década de 1980, a União promoveu 215 ações de reintegração de posse contra os moradores do Horto, com o argumento de uso indevido e ocupação irregular de terra pública, sem que houvesse qualquer proposta de alternativa habitacional ou mesmo indenização. As ações foram julgadas procedentes e tiveram seu trânsito em julgado em I990, contudo, sob forte resistência da Comunidade do Horto, poucas famílias foram removidas.

Em março de 20II, a Secretaria de Patrimônio da União(SPU), em parceira com o Laboratório de Habitação da Universidade Federal do Rio de Janeiro (LabHab/UFRJ), elaborou plano para a regularização fundiária e urbanística da Comunidade do Horto. Com base em visitas técnicas, levantamento socioeconômico da Comunidade do Horto e análise dos aspectos ambientais e urbanísticos da região, o plano elaborado compatibiliza os interesses de expansão do IPJB com o direito de permanecer das famílias do Horto. O projeto contempla as áreas do Jardim Botânico, do Horto e parcialmente do Condomínio Canto e Mello; propõe a utilização de I3\% dessa área para a permanência da Comunidade do Horto, a partir da realocação de 88 famílias na própria região; e a consolidação de infraestrutura urbana, considerando as características culturais e ambientais da área. ${ }^{8}$

No curso da implantação do projeto, a Associação de Moradores e Amigos do Jardim Botânico (AMAJB) apresentou denúncia ao Tribunal de Contas da União (TCU) alegando que a legitimação da posse dos moradores representaria mau uso do bem público. Com a publicação do Relatório TC 032.772.2010-6 e do Acordão 2380.2012, o TCU decidiu pela anulação do projeto de regularização fundiária elaborado pela SPU em convênio com a UFRJ.

A mesma decisão do TCU determinou a criação de comissão ${ }^{9}$ com objetivo de definir a área de interesse do IPJB, o que, em última instância, levaria à remoção das famílias inseridas no perímetro indicado. O relatório final da comissão orientou a remoção de $80 \%$ da Comunidade do Horto, o que significaria mais de 2 mil pessoas (MENDONÇA, 20I6b). Em 20I8, a União iniciou 17 novos processos coletivos de reintegração de posse que recaem sobre aproximadamente 250 casas, sem previsão de alternativa habitacional ou indenização. Nas ações de reintegração de posse a União afirma que:

\footnotetext{
${ }^{7}$ Lei Federal no 2.175/1971; cf. Mendonça (2016a).

${ }^{8}$ Disponível em: <http://www.hortofica.com.br/>. Acesso em: 10 jun. 2018.

${ }^{9}$ A comissão foi formada por membros do Ministério do Meio Ambiente, Ministério da Cultura e Ministério do Planejamento, bem como suas autarquias: Instituto de Pesquisa do Jardim Botânico, Secretaria de Patrimônio da União de Brasília e Instituto do Patrimônio Histórico e Artístico Nacional .
} 
Ocorre que, ao longo dos anos, este patrimônio do Brasil e da humanidade [Jardim Botânico] teve porção relevante do seu território invadida, totalizando mais de 500 ocupações irregulares, abarcando desde residências de classe média alta a construções típicas de comunidades à margem dos serviços sociais e urbanos básicos. (RIO DE JANEIRO, 2OII).

Sobre isso, importa perceber que a Comunidade do Horto é tratada como invasora da área do Jardim Botânico, contrariando o histórico de ocupação das famílias vinculado às instituições públicas e privadas que em algum momento estiveram presentes na região. Isso porque, ao longo do tempo, o Jardim Botânico e as fábricas de pólvora e tecido, formal ou informalmente, autorizaram a construção de moradias para seus funcionários, assim, as gerações de famílias formaram a Comunidade do Horto. Ademais, a citação anterior evidencia o tratamento diferenciado entre as comunidades de baixa renda e as residências de classe média alta: enquanto as primeiras vivem sob ameaça de remoção as segundas tiveram sua residência assegurada, como se verá adiante.

O falacioso argumento da incompatibilidade da moradia com a preservação do meio ambiente também tem sido mobilizado pelo Poder Público nas ações de remoção, quando afirmam que "as invasões e seus usos impróprios têm se mostrado como os principais obstáculos para os avanços institucionais do JBRJ, marcadamente para a expansão e integração das atividades de conservação in situ e ex situ" (RIO DE JANEIRO, 2OII). Tal afirmação se mostra incongruente com a realidade, quando se nota que o modo de vida da Comunidade do Horto é estreitamente relacionado com o meio ambiente natural ao seu entorno. Em entrevistas realizadas com os moradores, percebe-se presente a memória de suas infâncias na Floresta da Tijuca, inclusive com identificação de espécies da flora e da fauna da região, para além da preocupação com os impactos gerados, tal como a destinação do lixo da Comunidade do Horto. Somando-se a isso, o modo de vida da Comunidade do Horto se apresenta em consonância com o estabelecido na Constituição Federal de I988, que rompe com o entendimento do ambiente apenas no que tange seus aspectos biológicos, e assegura uma interpretação integrada das dimensões naturais e culturais do ambiente.

A fragilidade da situação fundiária das populações empobrecidas da cidade não é obra do acaso, considerando-se o caráter capitalista da reprodução urbana, as áreas centrais que não estejam formalmente regularizadas são mais afetadas pelo capital especulativo (HARVEY, 20I4). ${ }^{10} \mathrm{~A}$ consequência disso é a maior vulnerabilidade dessas moradias informais diante das políticas de remoções. Quando se investiga o processo de remoção da Comunidade do Horto, é inafastável seu fundamento na especulação imobiliária e na gentrificação de determinadas áreas da cidade. Nesse sentido, cabe destacar que os dados socioeconômicos produzidos pela SPU e pela

\footnotetext{
${ }^{10}$ Embora a formalização da relação jurídica que justifica a permanência não seja suficiente para frear processos de remoção, como vimos no caso da Vila Autódromo, em que muitos moradores possuíam contrato de concessão de direito real de uso.
} 
UFRJ no projeto de regularização fundiária apontam que 70\% das famílias do Horto apresentam renda entre zero e cinco salários-mínimos (UNIVERSIDADE FEDERAL DO RIO DE JANEIRO, 20II), enquanto a área que eles ocupam foi avaliada em Io,6 bilhões de reais (SCHMIDT, 20I8).

A vulnerabilidade econômica é um fator central nas dinâmicas de reordenação da cidade, no entanto, ao levar-se em consideração a composição demográfica das favelas e as relações de poder presentes nos processos de remoção, o racismo aparece como motivação somada às questões de classe (SANTOS, 2017). Dados do censo de 2010 do Instituto Brasileiro de Geografia e Estatística (IBGE) mostram que demograficamente a Comunidade do Horto é constituída majoritariamente por homens e mulheres negras; 62,I\% consideram-se pretos ou pardos e $37 \%$ brancas(os). Os números ganham sentido quando comparados com os do bairro onde a Comunidade do Horto está inserida: no Jardim Botânico, $82,8 \%$ dos moradores se declaram brancos e $16,7 \%$ pretos ou pardos. ${ }^{11}$

Em 2013, após solicitação dos moradores, a Consultoria Jurídica do Ministério do Planejamento, Desenvolvimento e Gestão (CONJUR/MPOG) emitiu parecer reconhecendo o direito à moradia da Comunidade do Horto, a ser efetivado por meio de Concessão de Uso Especial para fins de Moradia (CUEM). Contudo, a CUEM seria reconhecida em imóvel diverso da ocupação atual da Comunidade do Horto, por considerar-se parte da região de interesse do IPJB e como área de risco (com exceção da localidade Dona Castorina, que teve o direito outorgado no próprio imóvel, e, por isso, não enfrenta processo de remoção). Somando-se a isso, importa destacar que as ações judiciais que pretendem as remoções não estabelecem moradia alternativa, além de não haver qualquer política pública elaborada para realocação da Comunidade do Horto.

O IPJB tem se posicionado no sentido da incompatibilidade da permanência da Comunidade do Horto com seus interesses de expansão. Em recente entrevista, o diretor do IPJB, Sergio Besserman, questiona:

O Jardim Botânico de Paris tem pessoas morando dentro do Jardim Botânico de Paris? O Kew Gardens, em Londres, tem pessoas morando dentro do Kew Gardens? Não é compatível com o funcionamento de uma instituição de pesquisa e um centro de visitação. Nós não tivemos expansão, exceto aquilo que já era normalmente considerado do Jardim Botânico, inclusive a própria área da comunidade. Que sempre foi considerada, até pela própria comunidade, uma ocupação em um terreno do Jardim Botânico. (VIGNA, 20I8).

Dadas as considerações apresentadas, é possível perceber que o conflito existente hoje na região se estrutura a partir dos interesses públicos e privados, sem que se leve em consideração o direito de permanência dos moradores, o que se agrava pelas características de raça e classe da Comunidade do Horto.

\footnotetext{
${ }^{11}$ Disponível em: <https://censo2010.ibge.gov.br/painel/?nivel=st>. Acesso em: 12 jun. 2018.
} 


\section{Uma questão de raça e classe: o "direito de permanecer" do Condomínio Canto e Mello prevaleceu em relação a qualquer norma ambiental}

O Condomínio Parque Canto e Mello foi construído na Rua João Borges, localizado no bairro da Gávea, em local conhecido como Alto Gávea. Os proprietários submeteram o projeto do condomínio à prefeitura em I984, que ocupava uma área de 63.050 metros quadrados, com 25 lotes, mas o projeto não foi aprovado por ofensa às normas em vigor. ${ }^{12}$ Mesmo assim, as edificações foram construídas e, já em I99I, existiam I9 casas, sendo oito concluídas (duas em madeira e seis em alvenaria), com algumas habitadas, e II não concluídas. ${ }^{13}$

Em I99I, foi ajuizada uma ação que buscava a reparação dos danos ambientais provocados pela construção ilegal do condomínio, com pedido de demolição das construções, fechamento dos logradouros abertos e replantio da vegetação, tendo em vista sua instalação em área não edificável pela legislação ambiental e urbanística. ${ }^{14}$

Havia um acompanhamento muito próximo, inclusive com elaboração de denúncias, por parte da Associação de Moradores da Gávea (AMAGÁVEA), o que até foi objeto de destaque por um dos proprietários (Leonel do Canto e Mello) em depoimento judicial: "[...] que a única restrição que faz aos membros da AMAGÁVEA é a pressão que exerce contra o condomínio a despeito da preocupação da família do interrogando em fazer a preservação da floresta [...] que se não fosse o zelo da família a área do condomínio talvez tivesse sido ocupada por favelados" (depoimento judicial do acusado em 27 de maio de I99I).

Importante destacar, ainda, que os proprietários sabiam que se tratava de construções ilegais. Primeiro porque, como afirmado anteriormente, haviam submetido o projeto à Prefeitura, e este não foi aprovado. Segundo, pois se verifica em depoimentos feitos em juízo de pelo menos dois proprietários; um afirma que vendeu, embora soubesse que as construções eram proibidas (depoimento de Ronaldo Pereira do Canto e Mello em 29/05/199I) e o outro "que as pessoas adquiriram as terras, digo, as áreas, pagaram preço baixo porque sabiam que a construção local era proibida e por isso o interrogando crê que elas estão sendo levantadas sem projeto pelo município [...]" (depoimento de Leonel de Canto e Mello, em 27 de maio de I99i).

\footnotetext{
${ }^{12}$ Na oportunidade, em 1984, atestou-se que não existiam prédios ou quaisquer benfeitorias no local, bem como apenas $50 \%$ das vias que estavam abertas em 1991 já existiam em meados de 1980.

${ }^{13}$ As informações aqui relatadas e analisadas foram, em grande maioria, obtidas na ação judicial proposta pelo Ministério Público Estadual e Município do Rio de Janeiro, em face de determinados proprietários. Nessa ação judicial, foram produzidos inúmeros relatórios técnicos e documentos oficiais que contêm as informações necessárias para a análise proposta neste artigo. Ação judicial 3.345/1991 (numeração antiga)/1991.001.044112-4 (numeração atual).

${ }^{14}$ De acordo com a petição inicial da ação, os "réus co-proprietários do terreno situado à Rua João Borges, 240, Gávea, consoante certidões passadas pelo $2^{\circ}$ Ofício de Registro de Imóveis, [...] vem promovendo verdadeira retaliação da área em lotes irregulares, contrariando frontalmente o disposto no supra citado artigo 163 do Decreto Municipal 322, de 03.03.1976, já que a área, por situar-se em encosta acima da curva de nível de 100m (cem metros) a partir do nível do mar, está enquadrada como 'Zona Especial - ZE1', considerada por este dispositivo “Área de Reserva Florestal'”. A construção do condomínio ofenderia também o então Código Florestal (hoje a revogada Lei no 4.771/1965) que considerava a área como sendo de preservação permanente, ou seja, igualmente não edificável. Além de parcelamento ilegal do solo para implantação do que seria denominado de "Condomínio Parque Canto e Mello", a conduta dos réus ainda inclui a abertura de logradouros clandestinos, em ofensa à Lei de Parcelamento do Solo Urbano (Lei no 6.766/1979).
} 
Outro fato tão grave quanto parece ser a continuação das obras, mesmo com o ajuizamento da ação e com o deferimento, em 23 de maio de I99I, de medida judicial liminar para determinar a abstenção aos réus de promoverem novos desmatamentos e/ou prosseguirem na construção de edifícios de qualquer espécie, assim como consentir que terceiros o façam na área de sua propriedade. Tanto assim que, em 2003, quando realizada nova perícia, outros 17 imóveis foram erguidos, somando-se aos oito que já haviam sido construídos entre I984 (quando o projeto não foi aprovado) e I99I (ano da propositura da ação); além disso, um 26o imóvel estava sendo construído.

Ou seja, os proprietários tinham pleno conhecimento de que as construções eram proibidas e, ainda que, a princípio, não seriam passíveis de regularização. E, além de um descumprimento manifesto às normas ambientais e urbanísticas, demonstraram um profundo desrespeito às decisões judiciais, como se soubessem que, ao final, tudo restaria resolvido e eles poderiam viver tranquilamente em suas casas em região valorizada da cidade do Rio de Janeiro - como de fato aconteceu.

Embora o condomínio esteja localizado parcialmente no interior do IPJB, constando, ainda, informações de que duas casas do condomínio estão avançando sobre os limites do parque (ALDÉ, 2005a), não se encontrou nenhuma manifestação do Jardim Botânico a respeito.

A sentença (decisão de primeira instância) foi proferida em janeiro de 20II, no sentido da improcedência da ação judicial por não terem sido comprovados os danos ambientais causados pela construção das casas. De acordo com a sentença,

[...] a realidade destes autos não aponta, de forma alguma, para a ocorrência de dano ambiental, sendo de salientar que, se dano ocorre, se desenvolve bem ao lado da área em tela - favela da Rocinha - e nada, rigorosamente nada, foi feito para coibir o desmatamento. Apenar os réus pelas alterações mínimas feitas na vegetação, sem potencial lesivo e ainda capazes de proteger o espaço de invasões, seria ir na contramão da defesa do meio ambiente. (RIO DE JANEIRO, 2OII).

Ou seja, a sentença, além de afirmar que sequer existiu dano ambiental, utiliza-se do "perigo da favelização" para justificar a permanência das casas.

Essa sentença foi reformada em segunda instância, que entendeu terem sido comprovados os danos ambientais, destacando as conclusões do perito no sentido de que houve

[...] grande impacto ao meio ambiente, típico de ocupação antrópica de encostas e elevações, tais como, impermeabilização do solo, alteração da drenagem pluvial natural, retıirada de parte da vegetação e com perda de parcela da abundante e diversificadas espécies da flora, provocando alguma evasão de espécies da fauna [...], e, bem assim, desestabilização do meio geofísico, maior exposição do solo local às intempéries, com potencial risco de ocorrência de processos erosivos, alteração da drenagem natural do terreno, a ocasionar escoamento desordenado em alguns pontos e o carreamento de partículas de solo e restos vegetais, com o 
respectivo depósito nas galerias de drenagens e/ou recursos hídricos próximos, a ensejar possível assoreamento e aumento do risco de enchentes (RIO DE JANEIRO, 2OII $)^{15}$

A respeito desses danos ambientais, é importante lembrar que, no início de 20Io, uma das residências do condomínio Canto e Mello desabou, denotando a desestabilização do meio geofísico antes destacado (SILVA, 2010, p. 93).

Ocorre, contudo, que a perícia concluiu que os danos ambientais provocados pela reparação seriam maiores que manter as construções no local, ainda mais se considerar que os "réus estão reflorestando e 'protegendo' a área, impedindo que se façam edículas, em rígido sistema condominial" (RIO DE JANEIRO, 2OII). Conclui o perito que a demolição das edificações seria "medida de extremo radicalismo", já que as características biológicas do local não "suportariam tais intervenções" (demolições, movimentos de máquinas e caminhões), sugerindo medidas que vão desde impedir novas construções no condomínio, reflorestar, realizar tratamento paisagístico nas residências e até mesmo manter vigilância e segurança de modo a evitar possíveis invasões. ${ }^{16}$

Relevante destacar a justificativa do vereador Alberto Salles para o projeto de Lei $\mathrm{n}^{\mathrm{o}}$ I859/2008, que pretende alterar o Projeto de Alinhamento e Loteamento (PAL) com objetivo de regularizar o condomínio Parque Canto e Mello, no sentido de que "o mesmo já existe há um longo tempo, pagando IPTU pelas benfeitorias já executadas e evitando-se assim, com sua legalização, a formação de nova favela" (RIO DE JANEIRO, 2008).

Em resumo, trata-se de um caso exemplar do Direito brasileiro de manejo das normas ambientais para permitir a manutenção de construções de alto padrão, ainda que tenham sido construídas em flagrante e conhecida ilegalidade ambiental e urbanística, com descumprimento de decisão judicial. A partir de uma análise conjunta com o caso da Comunidade do Horto Florestal, pretende-se levantar questões sobre racismo a mbiental na cidade do Rio de Janeiro.

\section{Uma aproximação necessária entre o caso da Comunidade do Horto Florestal e do Condomínio Canto e Mello}

Os casos da Comunidade do Horto Florestal e do Condomínio Canto e Mello, anteriormente relatados, podem (e devem) ser interpretados conjuntamente com o objetivo de refletir sobre a maneira como o Direito vem sendo manejado para beneficiar classes dominantes e aprofundar desigualdades territoriais que caracterizam a ocupação da cidade. Nesse sentido, não se trata de

\footnotetext{
${ }^{15}$ Embora não tenha sido determinada a demolição, os proprietários foram condenados a indenizar pelos danos comprovadamente causados, em valor equivalente ao prejuízo que suportariam pela demolição de todos os prédios nele erigidos e pela recuperação florestal do local, bem como a adotar as medidas descritas pelo perito.

${ }^{16}$ À época, o advogado de um dos réus afirmou que a decisão atende aos interesses dos moradores que não queriam a demolição e que já faziam as medidas de recomposição da área. Nas palavras do advogado: "A preservação do local é de interesse dos moradores. Eles já fazem a jardinagem e embelezam a área. O pedido de recomposição ambiental feito pela Justiça já está sendo atendido. A decisão de não demolir as casas também está sacramentada. Agora vai ser iniciada a perícia no local para calcular o valor das indenizações. Esta será uma nova e longa fase do processo" (BORGES, 2012).
} 
casos isolados ou situações excepcionais, mas de um modo de agir, consolidado ao longo de séculos, inclusive após a edição da Constituição democrática de 1988, em que a interpretação das normas jurídicas reforça desigualdades sociais.

Inicialmente, cabe destacar que as duas localidades são muito semelhantes, com a mesma biodiversidade, e bastante próximas, distando cerca de 200 metros, conforme aponta o Mapa I.

Mapa 1. Distância mais próxima entre o Condomínio Canto e Mello e a Comunidade do Horto Florestal.

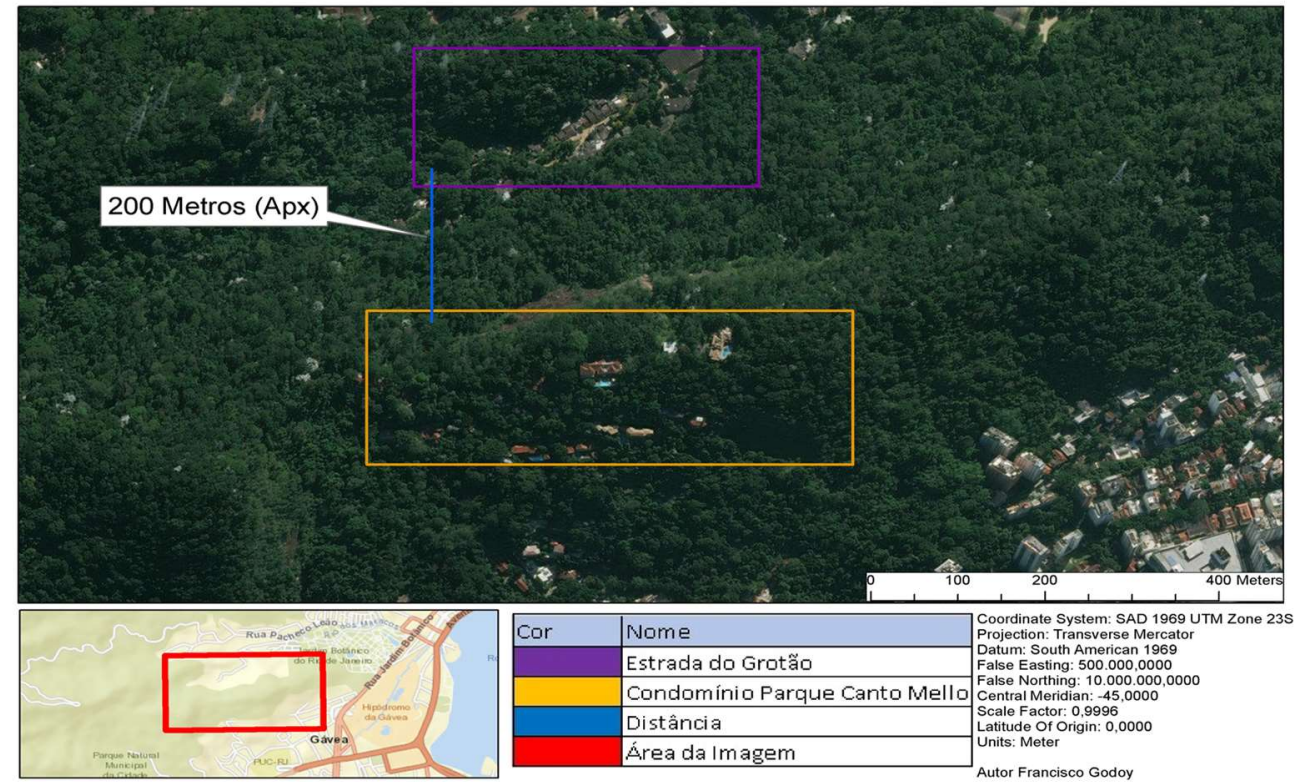

Mapa: Francisco Godoy, 2018.

Embora tão próximas, a interpretação das normas no caso do Condomínio Canto e Mello, contudo, foi completamente diversa do que se está se desenhando com as decisões individuais de remoção dos moradores da Comunidade do Horto, especialmente diante da disparidade do discurso ambiental no campo do Direito, bem como em relação ao tratamento dispendido aos envolvidos.

O Condomínio Canto e Mello, depois de um longo processo judicial, obteve o direito de manter suas construções, mesmo tendo se instalado em flagrante ilegalidade. Os moradores da Comunidade do Horto sofrem a pressão pela remoção de suas residências há mais de 30 anos, com algumas casas já removidas, em processo que desconsidera a legalidade inicial das construções e a relação dos moradores com o local.

Os moradores do Horto são tratados como invasores, inclusive assim são denominados em ações judiciais, desconsiderando-se seus vínculos jurídicos anteriores com o Poder Público que os autorizou a construir as residências no local. Ao contrário, em nenhum momento os proprietários do condomínio foram assim denominados. Poder-se-ia argumentar que se trata de uma questão de título de propriedade. Não nos parece, já que as referências à invasão ou a invasores se dirigem à favela ou ao pobre, como se pode constatar na sentença e no laudo do perito no processo judicial do condomínio. A sentença expressamente exterioriza a preocupação com a expansão da favela, no sentido de que melhor um condomínio de luxo do que uma ocupação irregular de baixa renda. 
O perito, em manifestação acolhida pelo acórdão, estabelece como uma das medidas compensatórias a vigilância contra possíveis invasores. E quem seriam esses possíveis invasores? Certamente não os condôminos.

O racismo aparece também nas reportagens que tratam do caso, podendo-se destacar desde o uso constante da palavra "invasor", até mesmo as conclusões a respeito da tática de forçar que as pessoas se mudem de suas casas, como: "Para dar certo, os invasores teriam que se sentir incomodados com sua situação. Se não se sentiram até hoje, dificilmente uma caprichada jardinagem em volta de suas casas é que vai constrangê-los" (ALDÉ, 2005a).

Além disso, o discurso ambiental veiculado para justificar a remoção dos moradores do Horto foi facilmente desarticulado para permanência do Canto e Mello. No caso do Horto, há uma justificativa pautada na relevância ambiental da região e na perda para toda a cidade de um "ativo", ${ }^{17}$ buscando um argumento supostamente universal para agregar mais defensores em torno dessas medidas. No Canto e Mello, chegou-se, inclusive, a afirmar a inexistência de dano ambiental, como o fez a juíza de primeira instância, quando este restou devidamente comprovado ao longo de toda a ação judicial. A decisão de segunda instância não foi tão longe, tampouco prendeu-se à importância ambiental da área. No acórdão, decisão final do caso, a questão ambiental, como um obstáculo a ser superado, é contornada para garantir a permanência das casas do condomínio.

O modo de vida dos moradores da Comunidade do Horto envolve uma integração com o entorno, inclusive com o ambiente, o que igualmente não é levado em consideração, tanto pelo Poder Judiciário quanto pelo próprio Jardim Botânico. Essa relação não está em discussão no caso do condomínio, embora a "integração paisagística" do local tenha sido levada em consideração para conclusão de que a demolição das casas seria uma intervenção radical.

A permanência dos moradores do Horto envolve um direito constitucional que não está em discussão no Condomínio Canto e Mello: o direito à moradia. Nesse sentido, em termos de direitos envolvidos, há muito mais em jogo para os moradores do Horto do que para os condôminos do Canto e Mello.

Por fim, buscando-se discutir de modo sistêmico o uso do Direito, tem-se que a remoção dos moradores da Comunidade do Horto e a permanência das casas do condomínio afrontam diretamente as normas constitucionais e evidenciam o racismo ambiental, consolidando o modo desigual de ocupação da cidade, conforme será visto a seguir.

\footnotetext{
${ }^{17}$ Esse discurso pode ser percebido nas palavras do então presidente do Jardim Botânico em: <https://globosatplay.globo.com/canalbrasil/v/6581232/>. Acesso em: 14 jun. 2018.
} 
Considerações finais: a continuidade de práticas de racismo ambiental na cidade do Rio de Janeiro

Os casos relatados destacam situações de racismo ambiental ao ser promovida a remoção de moradores e seu deslocamento para áreas periféricas da cidade, de modo a intensificar a situação de desigualdades sociais por meio da interpretação seletiva do Direito.

Há vasta literatura no sentido de que os efeitos da degradação ambiental - autorizados ou não - atingem as pessoas de modo distinto, a depender da raça ou da classe social. Nesse sentido, as consequências negativas oriundas de desrespeito ao equilíbrio do ambiente, dentre outros fenômenos, não são democráticas, tendendo a alcançar grupos e indivíduos pertencentes a setores menos favorecidos da sociedade. Além disso, o acesso a recursos naturais atinge distintamente as pessoas, a depender da classe social ou da raça. Bullard (2004) afirma que o "racismo ambiental é uma forma de discriminação institucionalizada". A discriminação institucional é definida como "ações ou práticas conduzidas pelos membros dos grupos (raciais ou étnicos) dominantes com impactos diferenciados e negativos para os membros dos grupos (raciais ou étnicos) subordinados" (p. 43).

A degradação ambiental é estrutural do modo de desenvolvimento em curso e aponta "de forma explícita, a nada surpreendente constatação: na sociedade capitalista é estruturalmente inevitável a ocorrência simultânea do desenvolvimento e subdesenvolvimento, da extrema concentração de renda e crescente extensão da miséria, tanto em âmbito global como no plano nacional" (COUTINHO, 2004, p. 49). Nesse sentido, "se há diferença nos graus de exposição das populações aos males ambientais, isso não decorre de nenhuma condição natural, determinação geográfica ou casualidade histórica, mas de processos sociais e políticos que distribuem de forma desigual a proteção ambiental" (ACSELRAD, 2009, p. 73).

O racismo a mbiental, no caso da Comunidade do Horto, é produzido por uma série de atos e omissões do Poder Público, mencionando-se a adoção das medidas voltadas à regularização fundiária quanto as diretamente relacionadas à remoção dos moradores. Nessas situações de racismo ambiental, os moradores do Horto suportam parcela desproporcional das consequências ambientais e, especificamente, acessam menos recursos ambientais presentes nos territórios (ACSELRAD, 2009, p. 4I). Estudos vêm sendo feitos para desvelar essa aplicação diferenciada das normas ambientais, interessando, para esta discussão, dois enfoques. O primeiro em relação ao abrandamento das normas ambientais para permitir a instalação e operação de empresas e atividades de maior impacto social e ambiental em áreas que, em geral, correspondem à residência de população de baixa renda. Seguindo esse raciocínio e comprovando-se o argumento anterior, a permanência de moradores negros em áreas valorizadas da cidade não é tolerada e, para tanto, usadas políticas públicas com objetivo de removê-los para aquelas "zonas de sacrifício". ${ }^{18} \mathrm{Na}$

\footnotetext{
${ }^{18}$ Conforme destacado por Viégas ([200?], on-line), "Na perspectiva dos estudiosos da desigualdade ambiental, o termo "zona de sacrifício" passou a designar locais onde há ocorrência de múltiplas práticas ambientalmente agressivas atingindo populações de baixa renda ou
} 
cidade do Rio de Janeiro, pode-se destacar parte da zona oeste como uma área destinatária dos moradores que foram removidos de suas casas, tanto pela ação direta do Poder Público quanto por meio da valorização de determinadas áreas que levaram à impossibilidade de permanência. $\mathrm{O}$ segundo enfoque vem destacando o uso da legislação a mbiental de modo mais rígido e intenso em relação a grupos tradicionalmente oprimidos na sociedade brasileira, como pobres, negros, comunidades tradicionais, povos indígenas e quilombolas. ${ }^{19}$

Compans (2007) discute a reedição desse discurso que associa a pobreza à degradação ambiental, destacando que, em relação à retomada das políticas de remoção, "têm se utilizado de um discurso que associa ocupação irregular do solo à degradação ambiental, como se fossem os pobres os únicos responsáveis pelo desmatamento e a poluição dos corpos hídricos ocorridos ao longo de décadas" (p. 97). Essa tese da autora fica bastante evidente tanto nos argumentos ventilados na ação judicial do Condomínio Canto e Mello, quanto no caso do próprio Horto. ${ }^{20}$

Ainda nesse sentido, Santos (2017) incorpora o elemento racial como central da exclusão das populações vulneráveis ao acesso a direitos fundamentais e sociais, tais como à moradia e ao ambiente, isso considerando que

[...] a opção do Estado em remover uma população majoritariamente composta por pessoas negras demonstra o racismo institucional inserido na questão. Este conceito foi pensado com o objetivo de evidenciar a reprodução do racismo, a seletividade racial, dentro das instituições públicas e privadas, mostrando os marcadores sociais da diferença entre negros e brancos. (SANTOS, 20I7, on-line).

É possível extrair das ações judiciais e das narrativas midiáticas em torno do processo de remoção da Comunidade do Horto, como destacado, composta majoritariamente por pessoas negras, a marginalização dos modos de vida dessa população como agressora do ambiente.

minorias étnicas. Tais populações são vítimas de impactos indesejáveis de grandes investimentos que se apropriam dos recursos existentes nos territórios, concentram renda e poder, ao mesmo tempo em que atingem a saúde de trabalhadores e a integridade de ecossistemas de que dependem".

${ }^{19}$ Em estudo sobre a diferença de aplicação da legislação ambiental em áreas muito próximas e igualmente relacionadas às obras olímpicas, Naback e Guimarães concluem: "Os casos da construção do Campo de Golfe e da remoção da Vila Autódromo desvelam que normas ambientais e urbanísticas podem ser manejadas de modo a se adequarem aos projetos ou interesses propostos. No caso do Campo de Golfe, houve a flexibilização da legislação ambiental e urbanística para permitir sua construção, desconsiderando a relevância ecológica do local, as normas que o preservavam e o histórico de instituição de áreas protegidas. As normas municipais foram alteradas e a licença ambiental concedida, sob o argumento principal da degradação do local. Essa mesma legislação ambiental teve sua importância largamente destacada para justificar a remoção da Vila Autódromo. Se, de um lado, ela foi manejada - e até mesmo desconsiderada - para permitir a construção do campo de golfe, de outro foi invocada de forma contundente para autorizar a remoção da favela. Observa-se, assim, que o manejo assimétrico de normas ambientais e urbanísticas é um dos mecanismos utilizados por esse projeto homogeneizador de cidade" (NABACK; GUIMARÃES, 2017, on-line).

${ }^{20}$ No mesmo sentido, as discussões de Gonçalves (2017) sobre a instrumentalização da noção de risco e seu uso para remoção das favelas cariocas. 
Enquanto os moradores do Jardim Botânico e da Gávea, em sua maioria brancos ${ }^{21}$ são tratados como protetores da região por não permitirem o avanço de moradias de baixa renda.

Importa destacar, ainda, o pouco peso político atribuído a setores da sociedade em relação às decisões que lhe afetam diretamente. Esse é um dos fatores que levam a situações de injustiça e racismo ambiental. Nesse sentido, às instâncias estatais pouco importam as manifestações dos moradores, inclusive quando veiculados por meios institucionalizados.

Nota-se que, a partir dos elementos relatados, o racismo ambiental consolida-se em diferentes dimensões, como decisões judicias, laudos periciais, manifestações de vereadores e reportagens. A análise desses casos em conjunto descortina a interpretação seletiva do Direito, consolidando privilégios para determinadas classes, com a manutenção das casas em área valorizada da Cidade e confirmando o racismo estrutural vigente na sociedade brasileira, de modo a intensificar as já tão marcantes desigualdades sociais.

\section{Referências}

ACSELRAD, H. O que é justiça ambiental? Rio de Janeiro: Garamond, 2009.

ALDÉ, L. Jardim das invasões. O Eco, II fev. 2005a. Disponível em: $<$ http://www.oeco.org.br/reportagens/978-oecoII425/>. Acesso em: 28 mai. 2018.

ALDÉ, L. Expansão ilimitada. O Eco, o7 out. 2005b. Disponível em: $<$ http://www.oeco.org.br/reportagens/I35I-oeco_I4I92/>. Acesso em: 28 mai. 2018.

BORGES, W. Casas não sairão de área florestal da Gávea. O Globo, I 4 jun. 20I2. Disponível em: $<$ https://oglobo.globo.com/rio/casas-nao-sairao-de-area-florestal-da-gavea4899094\#ixzz5GvHgt5bf>. Acesso em: 29 maio 2018.

RIO DE JANEIRO. $9^{\text {a }}$ Vara de Fazenda Pública. Sentença processo ${ }^{0}$ o0424OI-27.I991.8.I9.00oI (I99I.OOI.044II 2-4). Autor: Ministério Público do Estado do Rio de Janeiro. Rio de Janeiro, 24 jan. 2OII.

RIO DE JANEIRO. Câmara Municipal do Rio de Janeiro. Projeto de Lei no I.859, de 03 de setembro de 2008 .

BRASIL. Superior Tribunal de Justiça. $2^{\text {a }}$ Turma. Recurso Especial I.31O.47 I-SP. Relator: Ministro Herman Benjamin. Brasília, DJe or/o8/2013 (2013). Disponível em: $<$ https://ww2.stj.jus.br/processo/revista/inteiroteor/?num_registro=201102932952\&dt_publ icacao $=17 / 09 / 2013>$. Acesso em: 19 abr. 2018.

\footnotetext{
${ }^{21}$ Nos dados do senso do IBGE de 2010, constata-se que na Gávea 84\% dos moradores se declaram brancos e $16 \%$ negros, no Jardim Botânico 82,8\% brancos e 16,7\% negros, enquanto no Horto 37\% se declaram brancos e $62,1 \%$ negros (considerando-se negros as categorias "pretos" e "pardos"). Disponível em: <https://censo2010.ibge.gov.br/painel/?nivel=st>. Acesso em: 09 de julho de 2018.
} 
BULLARD, R. Enfrentando o racismo a mbiental no século XXI. In: ACSELRAD, H.; HERCULANO, S.; PÁDUA, J. A. Justiça ambiental e cidadania. Rio de Janeiro: Relume Dumará; Fundação Ford, 2004.

COMPANS, R. A cidade contra a favela: a nova ameaça ambiental. Revista Brasileira de Estudos Urbanos e Regionais, v. 9, n. I, p. 83-99, maio 2007.

COUTINHO, R. Direito ambiental das cidades: questões teórico-metodológicas. In: COUTINHO, R.; ROCCO, R. (Org.). O direito ambiental das cidades. Rio de Janeiro: DP\&A, 2004.

DAFLON, R. O conflito entre o social e o ambiental é falso. Canal Ibase. Disponível em: $<$ http://www.canalibase.org.br/os-falsos-argumentos-para-a-remocao-do-horto/>. Acesso em: 24 abr. 2018.

FARIAS, T.; ALVARENGA, L. J. A (in)justiça ambiental e o ideário constitucional de transformação da realidade: o direito em face da iníqua distribuição socioespacial de riscos e danos ecológicos. PERALTA, C. E.; ALVARENGA, L. J. AUGUSTIN, S. (Orgs.). Direito e justiça ambiental: diálogos interdisciplinares sobre a crise ecológica. Caxias do Sul, RS: Educs, 2014 .

GONÇALVES, R. S. A construção social do risco e as remoções das favelas cariocas. In: ENCONTRO ANUAL DA ANPOCS, 36., 2012, São Paulo . Anais... São Paulo: ANPOCS, 2012. Disponível em: <http://www.sigeventos.com.br/anpocs/inscricao/resumos/ooo5/TBRi359I.DOC $>$. Acesso em: 04 jul. 2018.

HARVEY, D. Cidades rebeldes. Do direito à cidade à revolução urbana. São Paulo: Martins Fontes, 2014.

MENDONÇA, R. da M. Horto florestal: uma crônica jurídica de avanços e retrocessos no direito à cidade no Rio de Janeiro. In: CORREIA, A. F.(Org.). Moradia e exclusão social na metrópole. Rio de Janeiro: Multifoco, 20I6a. p. 332-37I.

MENDONÇA, R. da M. Segurança da posse, consenso democrático e controle externo unilateral: avanços e retrocessos na história da ocupação do Horto Florestal, na cidade do Rio de Janeiro. Dissertação (Mestrado Acadêmico em Direito) - Universidade Estadual do Rio de Janeiro, Rio de Janeiro, 20I6b.

NABACK, C.; GUIMARÃES, V. T. Disputas em torno da moradia e do meio ambiente na região da Barra da Tijuca: os casos da Vila Autódromo e do Campo de Golfe Olímpico. In: ENCONTRO NACIONAL DA ASSOCIAÇÃO NACIONAL DE PÓS-GRADUAÇÃO E GRADUAÇÃO E PESQUISA EM PLANEJAMENTO URBANO E REGIONAL ENAPUR, 28., 20I7, São Paulo.

Desenvolvimento, crise e resistência: quais os caminhos do planejamento urbano e regional? São Paulo: FAUUSP, 20I7.v. I. Disponível em: http://anpur.org.br/xviienanpur/principal/publicacoes/XVII.ENANPUR_Anais/ST_Sessoes_ Tematicas/ST\%2O4/ST\%204.3/ST\%2O4.3-04.pdf Acesso em: 28 out. 2019. 
OST, F. A natureza à margem da lei: a ecologia à prova do direito. Lisboa: Instituto Piaget, 1995.

SANTILLI, J. Os "novos" direitos socioambientais. Revista Direito e Justiça: Reflexões Sociojurídicas, Porto Alegre: Ed. PUC-RS, ano VI, n. 9., nov. 2006.

SANTOS, C. C. P. dos. Elekô: mulheres negras na luta por direito à moradia na cidade do Rio de Janeiro. Dissertação (Mestrado Acadêmico em Sociologia e Direito) - Universidade Federal Fluminense, Niterói, 2017.

SCHMIDT, S. Jardim Botânico: Governo Dilma, já no fim, tentou manter moradores. O Globo, Rio de Janeiro, I8 maio 20I6. Disponível em: $<$ https://oglobo.globo.com/rio/jardim-botanicogoverno-dilma-ja-no-fim-tentou-manter-moradores-I9326526> Acesso em: I2 de jun. 2018.

SILVA, H. S. da. A remoção (re)pautada na cidade do Rio de Janeiro: discursos, mídia e resistências, 2005 a 20Io. Dissertação (mestrado) - Instituto de Pesquisa e Planejamento Urbano e Regional, Universidade Federal do Rio de Janeiro, Rio de Janeiro, 2010.

SOUZA, L. O. C. de. Horto Florestal: um lugar de memória da cidade do Rio de Janeiro. A construção do Museu do Horto e seu correspondente projeto social de memória. 2012. Disponível em: <https://www.maxwell.vrac.puc-rio.br/2 1757/21757.PDF $>$. Acesso em: 04 jul. 2018.

UNIVERSIDADE FEDERAL DO RIO DE JANEIRO. Laboratório de Habitação. Proposta Preliminar das Poligonais da Comunidade do Horto/Jardim Botânico e do Instituto de Pesquisas Jardim Botânico do Rio de Janeiro (Memorial Descritivo), 201 I.

VIÉGAS, R. N. Desigualdade ambiental e “zonas de sacrifício”. Portal Domínio Público. [20o?]. Disponível em: $<$ http://www.dominiopublico.gov.br/pesquisa/DetalheObraForm.do?select_action=\&co_obr $\mathrm{a}=\mathrm{I} 21969>$ Acesso em: 04 jul.2OI8.

VIGNA, A. Pobre sai, rico fica. Agência Pública, I6 mar. 20I7. Disponível em: $<$ https://apublica.org/20I7/o3/pobre-sai-rico-fica/>. Acesso em: 08 jul.20I8. 